\title{
Variations in Carbohydrate Content and Sucrose-Metabolizing Enzymes in Tomato (Solanum lycopersicum L.) Stamen Parts during Pollen Maturation
}

\author{
Etan Pressman, Rachel Shaked, Shmuel Shen, Leviah Altahan, Nurit Firon
}

Institute of Plant Sciences, The Volcani Center, ARO, Bet Dagan, Israel.

Email: \{pressman, shakedra, shmuels, leviah, vcfiron\}@volcani.agri.gov.il

Received July 25 ${ }^{\text {th }}$, 2011; revised August $25^{\text {th }}$, 2011; accepted September $6^{\text {th }}, 2011$

\begin{abstract}
The formation of mature and fertile pollen grains, taking place inside the anther, depends on supply of assimilates, in the form of sucrose, provided mainly by the leaves. Data is limited, however, with respect to the understanding of sucrose metabolism in microspores and the supporting tissues. The aims of the present work were to 1) follow the changes in total and relative concentrations of sucrose, glucose, fructose and starch in the stamen parts and microspores up until anthesis; 2) Follow the activities of sucrose-metabolism-related enzymes, in the anther walls fraction and microspores of the crop plant tomato. Sucrose was found to be partially cleaved in the filament, decreasing by more than twofold in the anther wall layers and the locular fluid, and to accumulate in the mature pollen grains, constituting $80 \%$ of total soluble sugars. Thus, sucrose was both the starting sugar, supporting microspore development, and the main carbohydrate accumulated at the end of the pollen-development program. The major invertase found to be active in both the anther wall layers and in maturing microspores was cell-wall-bound invertase. High fructokinase 2 and sucrose phosphate synthase activities during pollen maturation coincided with sucrose accumulation. The potential importance of sucrose accumulation during pollen dehydration phase and germination is discussed.
\end{abstract}

Keywords: Cell-Wall-Bound Invertase; Fructokinase; Microspores; Pollen; Sucrose; Sucrose Phosphate Synthase; Tomato

\section{Introduction}

The formation of mature and fertile male gametophytes, which takes place inside the anther, depends on assimilates, in the form of sucrose, provided by the leaves [1], with some contribution from the sporophytic tissues of the anther [2,3]. Male gametophyte development involves meiosis of pollen mother cells to form haploid tetrads which are covered by callose. Release of single, free microspores from each tetrad is achieved by callase secretion from the tapetal cells, comprising the innermost layer of the anther wall, which nourish the microspores and degenerate thereafter [4-6]. At this stage, the incoming sucrose molecules that arrive through the phloem continue to the developing microspores through the anther wall layers and the locular fluid that surrounds the microspores. Clement et al. [7] have suggested that the locular fluid represents the chemical link between the anther wall and the symplastically isolated pollen grains. Therefore, sugar nutrition of pollen widely depends upon the physiology of the sporophytic fraction, which regulates the amount of carbohydrates reaching the male gameto- phyte [2]. During the anther maturation phase, when the tapetum disappears and is unable to control any more the nutrient flow to the maturing gametophytes, it was demonstrated that the anther wall middle cell layer (ML1) is involved in the control of pollen sugar nutrition exhibiting a buffering effect [2]. Along the way from the vascular system to the gametophytes, sucrose molecules are cleaved and metabolized, serving as an immediate energy source or stored in the form of starch [8]. Castro and Clement [8] have recently demonstrated that in the anther of Lilium, glucose and fructose levels progressively decrease from the anther wall to the locular fluid and from the fluid to the microspores/pollen, suggesting that the developing pollen may act as a sink for carbohydrates that reach the anther. The same authors also suggested that the anther wall tissues may have a buffering function, storing nutrient surplus in starch grains and thus regulating the availability of soluble sugars in the whole anther.

Sucrose utilization is initiated by hydrolysis, catalyzed by two different enzymes: invertase (EC 3.2.1.26) and sucrose synthase (EC 2.4.1.13). The latter, localized in the cytoplasm, cleaves sucrose reversibly into fructose 
and UDP-glucose [9]. Three types of invertase are distinguished on the basis of their localization, solubility and $\mathrm{pH}$ optima $[10,11]$. Invertases with acidic $\mathrm{pH}$ optima are bound ionically to the cell wall (cell-wall-bound or extracellular invertases, termed CWI) or accumulate as soluble proteins in the vacuole (soluble or vacuolar invertases); those with neutral or slightly alkaline $\mathrm{pH}$ optima (neutral or alkaline invertases) are thought to accumulate in the cytoplasm [11,12]. All invertases cleave sucrose irreversibly to glucose and fructose. Following sucrose cleavage by invertase, the liberated fructose and glucose molecules are phosphorylated before undergoing further metabolism.

Sucrose phosphate synthase (SPS), is the enzyme that plays an important role in carbon partitioning-regulating starch production versus sugar accumulation in many physiological and developmental processes [13], such as water stress [14], diurnal carbohydrate allocation within the plant [15,16], and during flower [17], fruit [18] and cell-wall development [19]. SPS is the major enzyme involved in sucrose synthesis, using both UDP-glucose and fructose-6-P. Fructose-6-P, in turn, may be formed by phosphorylation of fructose by fructokinase [20].

In the present work, we followed soluble sugar and starch concentrations, as well as the sucrose: glucose: fructose ratios, in the four main parts of the stamen (the filament, anther walls, locular fluid and microspores/ pollen grains) during microspore maturation in tomato, a crop plant belonging to the Solanaceae family. To better characterize sugar metabolism in the maturing microspores, which serve as a sink and influence the direction of sugar movement in the anther, enzyme activities of soluble and cell-wall-bound invertases, sucrose synthase (Susy), fructokinase 1, fructokinase 2 and SPS were determined in the anther wall layers and in isolated microspores.

\section{Materials and Methods}

\subsection{Plant Material and Growth Conditions}

The tomato (Solanum lycopersicum L.) cultivar-Hazera 3017 was grown in a temperature-controlled greenhouse at The Volcani Center in Bet Dagan, Israel, under natural light conditions (day length of $13.5-14 \mathrm{~h}$ ) and day/night temperatures of $28 / 22^{\circ} \mathrm{C} \pm 2^{\circ} \mathrm{C}$ for 5 months. These environmental conditions have been found to ensure high pollen viability and germination [21].

Flower buds at 5, 3, 1 and 0 days before anthesis (A-5, A-3, A-1 and A, respectively, corresponding to vacuolated microspore, early binucleate, second vacuolation stages, and mature pollen, respectively [22] were sampled and anther parts were separated. At least 50 flower buds were used for each sample preparation. Each sam- ple served as a biological replicate and at least three replicates, sampled at different dates, were used for obtaining each data point.

\subsection{Isolation of Stamen Parts and Pollen Grains}

After separation of the filaments (easily distinguished from the anther), the anthers were dissected according to Aouali et al. [23]. Maturing microspores and pollen grains from immature and mature anthers, respectively, were obtained by slicing the anthers transversely and vortexing them in cold solution containing $2 \mathrm{mM}$ boric acid, $2 \mathrm{mM}$ calcium nitrate, $2 \mathrm{mM}$ magnesium sulfate and 1 $\mathrm{mM}$ potassium nitrate. The solution was then filtered through cheesecloth to separate out the anther walls, and the microspores, and pollen grains were separated from the locular fluid by centrifugation for $10 \mathrm{~min}$ at $8000 \mathrm{~g}$. For carbohydrate analysis, the released microspores and pollen grains, the anther walls and the locular fluid were immediately suspended in $80 \%$ ethanol at $75^{\circ} \mathrm{C}$ for 30 min and analysed, or frozen at $-70^{\circ} \mathrm{C}$. For enzyme activity assays, anther walls and maturing pollen grains were plunged into liquid nitrogen, and kept at $-70^{\circ} \mathrm{C}$ until use.

\subsection{Carbohydrate Analysis}

The carbohydrate concentrations in the samples were analysed according to Hubbard et al. [24] and Stoop and Pharr [25]. Ethanol-suspended samples were extracted three times in hot $80 \%(\mathrm{v} / \mathrm{v})$ ethanol. The supernatant was dried in vacuo at $40^{\circ} \mathrm{C}$ and resolubilized in water. Soluble sugars were determined by HPLC with a Fast Carbohydrate column (Bio-Rad, Richmond, CA, USA) operated at $85^{\circ} \mathrm{C}$, with deionized, degassed water as the eluent [25] and detection by a refractometer.

The insoluble residue that remained after ethanolic extraction was resuspended in $2 \mathrm{~mL}$ of $30 \mathrm{mM} \mathrm{HCl}$ and boiled for $30 \mathrm{~min}$. After cooling, the $\mathrm{pH}$ was adjusted to 4.5 with $\mathrm{KOH}$. The gelatinized starch was digested for 60 min at $50^{\circ} \mathrm{C}$ with approximately $36 \mathrm{U}$ of amyloglucosidase from Aspergillus oryza [24]. The reaction mixture was incubated at $25^{\circ} \mathrm{C}$ for $30 \mathrm{~min}$ and absorbance at $340 \mathrm{~nm}$ was measured. At least 3 biological replicates were used for each analysis and the data represent their average \pm SE.

\subsection{Enzyme Assays}

Activities of soluble and cell-wall-bound acid invertases, alkaline invertase and Susy were assayed as described by Miron et al. [26] and Schaffer et al. [27], respectively, using frozen anther walls or maturing microspores ground to a fine powder with liquid nitrogen. A chilled mortar and pestle was used for subsequent grinding in $2.0 \mathrm{~mL}$ chilled extraction buffer containing $50 \mathrm{mM}$ Hepes- $\mathrm{NaOH}$ 
pH 7.5, 5 mM MgCl $2,0.5$ mM Na-EDTA, 2.5 mM DTT, $2 \mathrm{mM}$ PMSF, $1 \%$ (w/v) insoluble polyvinylpyrrolidone (PVP), and $2 \mathrm{mM}$ diethyldithiocarbamic acid (DIECA). After centrifugation at $18,000 \mathrm{~g}$ for $30 \mathrm{~min}$, the supernatant was used to determine soluble acid invertase, alkaline invertase and Susy activities. The pellet was washed (at least three times) in the same buffer (until the supernatant from the last wash exhibited no invertase activity), after which the pellet was homogenised and incubated overnight in the same buffer containing $0.5 \mathrm{M} \mathrm{NaCl}$, at $4^{\circ} \mathrm{C}$, to release bound enzyme. After centrifugation at $18,000 \mathrm{~g}$ for $30 \mathrm{~min}$, the supernatant was designated the CWI fraction. Invertase and Susy activities were determined after $3 \mathrm{~h}$ of dialysis (longer dialysis times caused a reduction in Susy activity) of the respective fractions against extraction buffer diluted 1:2 (v/v), with five changes of dialysis buffer.

Acid invertase activity was determined in $60 \mathrm{mM}$ phosphate-citrate buffer $\mathrm{pH} 5$ containing $20 \mathrm{mM}$ sucrose and $0.2 \mathrm{~mL}$ enzyme extract in a final volume of $2 \mathrm{~mL}$ for 60 min at $37^{\circ} \mathrm{C}$, with enzyme blanks containing boiled enzyme extract. Reactions were terminated by immersing the reaction tubes in boiling water for 5 min, and the amount of glucose liberated was determined colorimetrically with dinitrosalicylic acid reagent [28].

Susy activity was assayed in the cleavage direction in $60 \mathrm{mM}$ phosphate-citrate buffer $\mathrm{pH} 7$ containing $50 \mathrm{mM}$ sucrose and $0.2 \mathrm{~mL}$ enzyme extract in a $2 \mathrm{~mL}$ reaction volume, for $60 \mathrm{~min}$ at $37^{\circ} \mathrm{C}$, using dinitrosalicylic acid to measure the released reducing sugar, as described above. The additional fructose produced at $\mathrm{pH} 7$ in the presence of $5 \mathrm{mM}$ UDP compared to that produced in reaction mixtures without UDP was attributed to Susy activity. Reactions were terminated by immersing the reaction tubes in boiling water for 5 min.

Alkaline invertase activity was assayed in the same reaction mixture under the same incubation conditions as Susy activity, but without adding UDP. Specific enzyme activity was expressed as the amount (nmol) of reducing sugar (glucose and fructose) released per minute per milligram protein. Protein concentrations were quantified according to Bradford [29].

Fructokinase activity was measured by an enzymelinked assay according to Schaffer and Petreikov [30]. The tissue was ground as described above and the extraction buffer contained $50 \mathrm{mM}$ Hepes-NaOH (pH 7.5), 1 $\mathrm{mM} \mathrm{MgCl} 2,1 \mathrm{mM}$ EDTA, $10 \mathrm{mM} \mathrm{KCl}, 2.5 \mathrm{mM}$ DTT, $1 \%$ insoluble PVP, $3 \mathrm{mM}$ DIECA and $1 \mathrm{mM}$ PMSF. After centrifugation at $18,000 \mathrm{~g}$ for $30 \mathrm{~min}$, the supernatant was kept on ice and precipitated with $80 \%$ (w/v) ammonium sulfate. The precipitate was resuspended in a buffer containing $50 \mathrm{mM}$ Hepes- $\mathrm{NaOH}(\mathrm{pH} 7.5)$ and $1 \mathrm{mM}$ DTT, and desalted on a Sephadex G-25 column. The assay buffer contained $30 \mathrm{mM}$ Hepes- $\mathrm{NaOH}(\mathrm{pH} 7.5)$, 0.5 or $3.0 \mathrm{mM} \mathrm{MgCl}_{2}$ (for assaying fructokinase 2 and fructokinase 1 , respectively), $9 \mathrm{mM} \mathrm{KCl,} 1 \mathrm{mM} \mathrm{NAD}, 1$ mM ATP, 1 unit of glucose-6-P dehydrogenase (Sigma) and 1 unit of phosphoglucoisomerase (type III, Sigma, St Louis, MO). The reaction was initiated with $1 \mathrm{mM}$ or 10 $\mathrm{mM}$ fructose, for fructokinase 2 and 1, respectively.

SPS was measured following extraction using a buffer containing $50 \mathrm{mM}$ Hepes- $\mathrm{NaOH}$ (pH 7.5), $5 \mathrm{mM} \mathrm{MgCl}_{2}$, $1 \mathrm{mM}$ EDTA, 0.05\% (v/v) Triton X-100, $2.5 \mathrm{mM}$ DTT and $1 \mathrm{mM}$ PMSF according to Hubbard et al. [31]. A 5 mL Sephadex G-25 column was used for separating the proteins from the sugars. The assay was carried out according to Huber and Huber [15] in a buffer containing 50 $\mathrm{mM}$ Hepes-NaOH (pH 7.5), 15 mM MgCl 2,25 mM UDPglucose, $25 \mathrm{mM}$ glucose-6-P, $25 \mathrm{mM}$ fructose-6-P, for 30 min at $37^{\circ} \mathrm{C}$, followed by the addition of an equal volume of $30 \%(\mathrm{w} / \mathrm{v}) \mathrm{KOH}$ and boiling for $10 \mathrm{~min}$. The resultant sugar concentration was determined colorimetrically following the addition of Anthron reagent $(0.1 \% \mathrm{w} / \mathrm{v}$ in $72 \%$ $\mathrm{H}_{2} \mathrm{SO}_{4}$; Merck, Rosh Haain, Israel). For all enzyme activity measurements, tests were repeated 3 times.

\section{Results}

\subsection{Soluble Sugar and Starch Contents in the Stamen Parts}

In the filaments, total soluble sugar concentration ranged between 90 and $120 \mathrm{mg} \cdot \mathrm{g}$ dry weight $(\mathrm{DW})^{-1}$ during the tested flower bud developmental stages and was composed of sucrose, glucose and fructose (Figure 1(a)), indicating that sucrose hydrolysis had already begun in this part of the stamen. The concentrations of sucrose and fructose were similar (in the range of 35 to $60 \mathrm{mg} \cdot \mathrm{g} \cdot \mathrm{DW}^{-1}$ ) and about double that of glucose $\left(20 \mathrm{mg} \cdot \mathrm{g} \cdot \mathrm{DW}^{-1}\right)$ at all three examined developmental stages.

In the anther wall fraction, fructose became the major sugar (reaching a concentration of $120 \mathrm{mg} \cdot \mathrm{g} \cdot \mathrm{DW}^{-1}$ at A-3) and sucrose the minor one (about 30 to 20 $\mathrm{mg} \cdot \mathrm{g} \cdot \mathrm{DW}^{-1}$ at A-5 to A, respectively; Figure 1(b)). In the locular fluid, similar to the anther wall layers, sucrose levels were very low (reaching a concentration of 4 $\mathrm{mg} \cdot \mathrm{g} \cdot \mathrm{DW}^{-1}$ ) and fructose became the main sugar (reaching a concentration of $70 \mathrm{mg} \cdot \mathrm{g} \cdot \mathrm{DW}^{-1}$; Figure 1(c)). It is interesting to note that similar results were obtained for an additional member of the Solanaceae family (pepper) in which the locular fluid was found to be rich in fructose (ca. $60 \%$ of total soluble sugars) although the anther wall fraction contained low fructose levels and high levels of sucrose (data not shown).

The concentrations of the three sugars and the ratios among them changed dramatically in the maturing pollen 


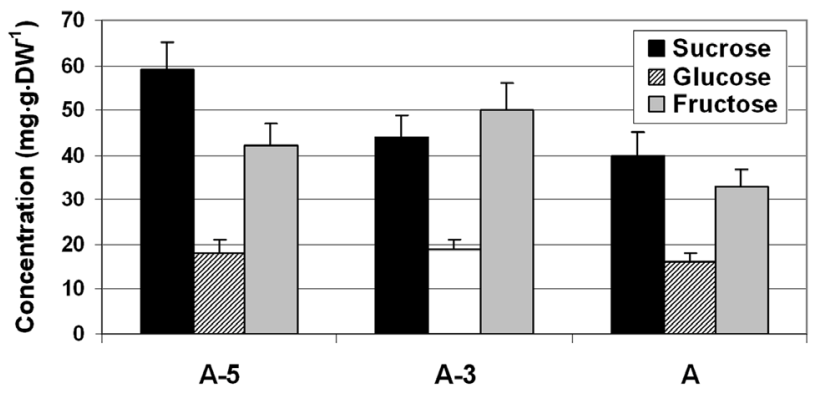

(a)

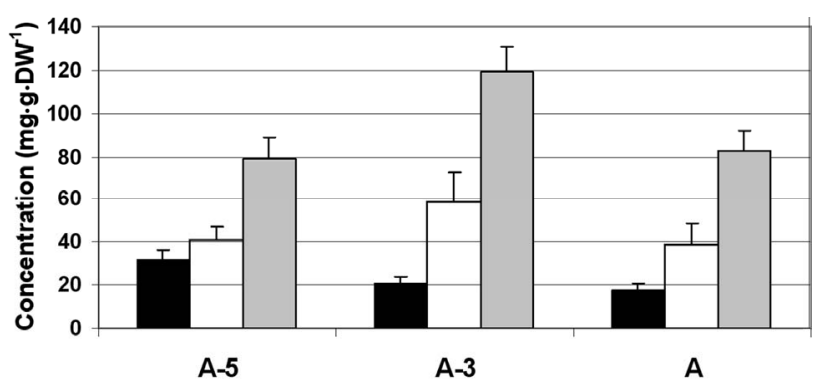

(b)

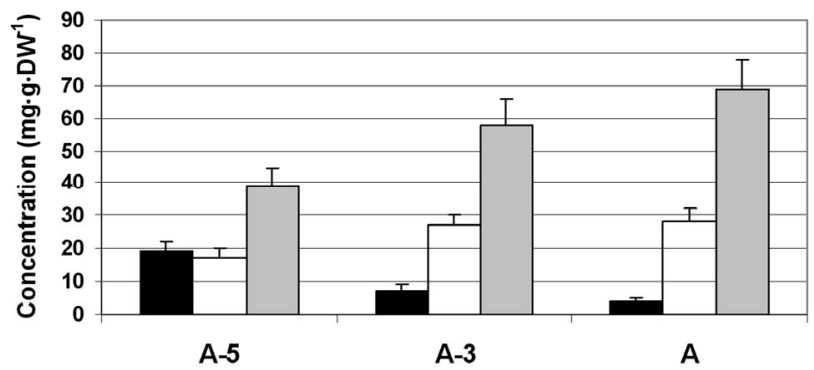

(c)

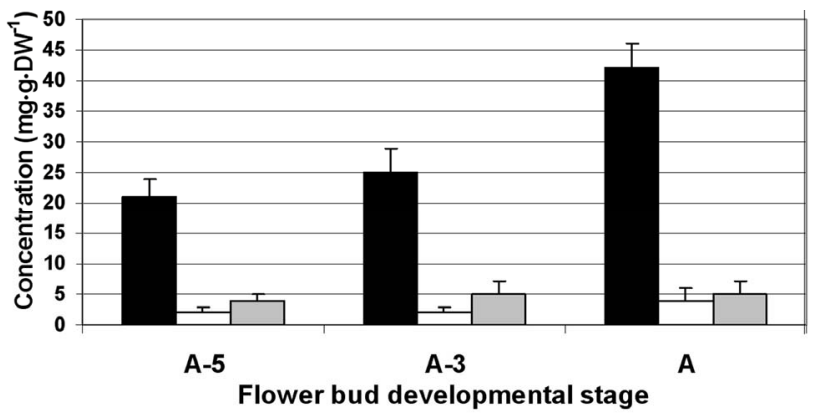

(d)

Figure 1. Changes in the concentration of sucrose, glucose and fructose in the stamen parts (filaments (a) anther walls (b) locular fluid (c) and pollen grains (d)) of maturing anthers of tomato cv. 3017 at three stages of development: 5, 3 and $0 \mathrm{~d}$ before anthesis (A-5, A-3 and $A$, respectively). Data represent an average of at least 3 biological replicates. Vertical bars represent $\mathrm{SE}$.

grains (Figure 1(d)). The major sugar in the maturing and mature pollen grains was sucrose, constituting $80 \%$ of the total soluble sugars. The results indicate sucrose accumulation during microspore maturation, exhibited by about twofold increase in mature pollen grains as compared to microspores at the A- 5 stage of development. The concentrations of glucose and fructose were very low, $5 \mathrm{mg} \cdot \mathrm{g} \cdot \mathrm{DW}^{-1}$ or less, throughout the tested developmental stages.

Starch levels in the anther walls were in the range of $70 \mathrm{mg} \cdot \mathrm{g} \cdot \mathrm{DW}^{-1}$ at stages A-5 and A-3, and decreased to $40 \mathrm{mg} \cdot \mathrm{g} \cdot \mathrm{DW}^{-1}$ at anthesis (stage A; Figure 2). The maturing pollen grains accumulated starch, the level of which peaked $3 \mathrm{~d}$ before anthesis and sharply decreased in mature pollen grains at anthesis (Figure 2).

\subsection{Invertase, Susy, Fructokinase and SPS Activity Patterns in Anther Layers and Isolated Microspores}

\subsubsection{Invertases and Susy}

In the anther wall fraction, both CWI and vacuolar invertase exhibited high activity, ranging from 300 to 645 $\mathrm{nmol} \cdot \mathrm{mg} \cdot \operatorname{protein}^{-1} \cdot \mathrm{min}^{-1}$. Highest CWI activity was detected at A-5, while highest vacuolar invertase activity was observed during the later stages of maturation (A-3 and A-1; Figure 3(a)).

In maturing microspores, the major invertase found to be active was CWI, which exhibited increasing activity (from 320 to $600 \mathrm{nmol} \cdot \mathrm{mg} \cdot$ protein $^{-1} \cdot \mathrm{min}^{-1}$ ) during maturation and several-fold higher activity than the other two invertases (Figure 3(a)). Activities of the soluble acid and neutral (alkaline) invertases were similar, in the range of $100 \mathrm{nmol} \cdot \mathrm{mg} \cdot$ protein $^{-1} \cdot \mathrm{min}^{-1}$ at the tested microspore developmental stages (Figure 3(a)). In the anther wall fraction, Susy activity (in the cleavage direction) was $15 \mathrm{nmol} \cdot \mathrm{mg} \cdot$ protein $^{-1} \cdot \mathrm{min}^{-1}$ at A-5 and increased to $79 \mathrm{nmol} \cdot \mathrm{mg} \cdot \operatorname{protein}^{-1} \cdot \mathrm{min}^{-1}$ at A-1 (Figure 3(b)). No Susy activity was detected in maturing and mature pollen grains.

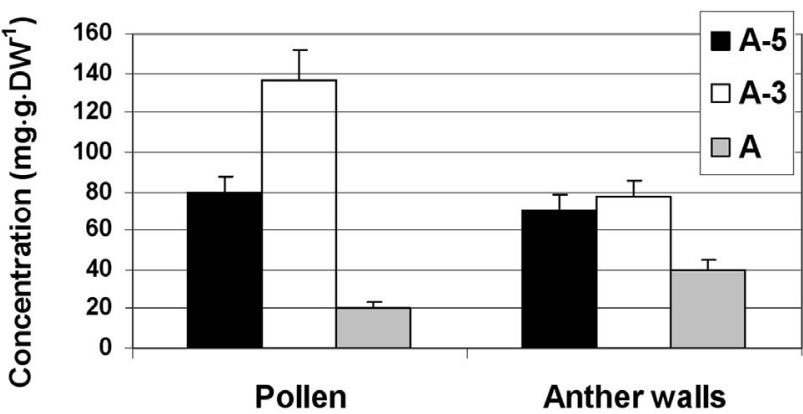

Figure 2. Changes in starch concentration in the anther walls and in the pollen grains of tomato $\mathrm{cv}$. 3017 at the late stages of anther maturation (5, 3 and $0 \mathrm{~d}$ before anthesis (A-5, A-3 and A, respectively). "Pollen" represents maturing microspores and mature pollen grains. Data represent an average of at least 3 biological replicates. Vertical bars represent $\mathrm{SE}$. 


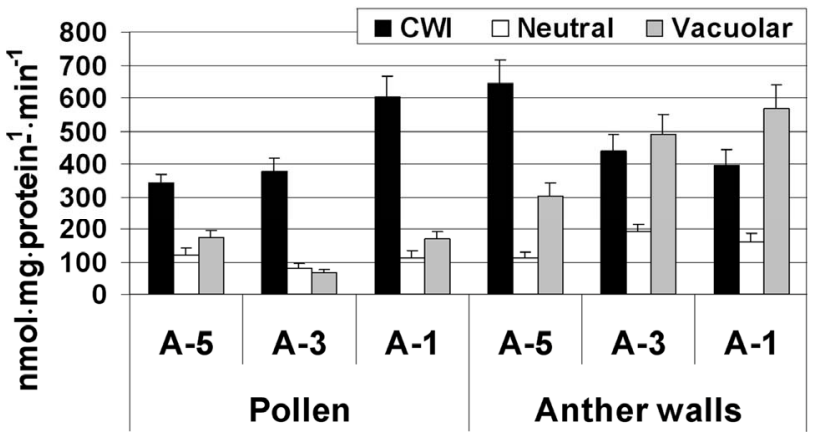

(a)

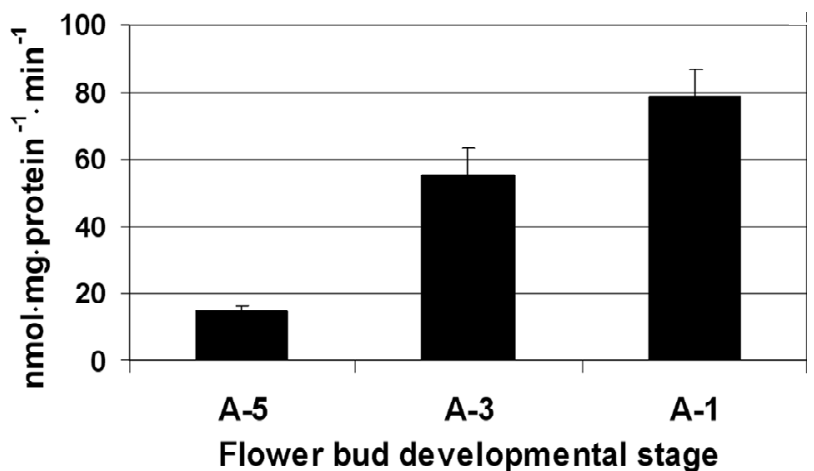

(b)

Figure 3. Changes in the activities of three invertases (a) and Susy (b) in tomato cv. 3017 maturing anther walls and pollen grains (A-5, A-3, A-1: 5, 3 and $1 \mathrm{~d}$ before anthesis, respectively; CWI: cell-wall-bound acid invertase). Susy activity was detected in the anther wall fraction only (b). "Pollen" represents maturing microspores. Data represent an average of at least 3 biological replicates. Vertical bars represent $\mathrm{SE}$.

\subsubsection{Fructokinases}

Fructokinase 2 was the major active fructokinase in both the anther wall fraction and maturing microspores (Figure 4). In the anther wall fraction, fructokinase 2 activity was in the range of 40 to $88 \mathrm{nmol} \cdot \mathrm{mg} \cdot$ protein $^{-1} \cdot \mathrm{min}^{-1}$, while the activity of fructokinase 1 was about tenfold lower (Figure 4). In the isolated microspores, fructokinase 2 exhibited a sharp increase in activity (more than fourfold) from developmental stage A-5 to A-3 (Figure 4). The activity of fructokinase 2 remained high, in the range of $250 \mathrm{nmol} \cdot \mathrm{mg} \cdot \operatorname{protein}^{-1} \cdot \mathrm{min}^{-1}$, at developmental stage A-1 (Figure 4). The activity of fructokinase 1 was relatively weak (although tenfold higher than the activity detected in the anther wall fraction) and exhibited a twofold in- crease at A-3, reaching 100 $\mathrm{nmol} \cdot \mathrm{mg} \cdot \operatorname{protein}^{-1} \cdot \mathrm{min}^{-1}$ (Figure 4).

\subsubsection{SPS}

In the anther wall layers, SPS activity was relatively low, ranging from 17 to $58 \mathrm{nmol}$ sucrose $\mathrm{mg} \cdot$ protein $^{-1} \cdot \mathrm{min}^{-1}$ at A-5 and A-1, respectively (Figure 5(a)). In the iso-

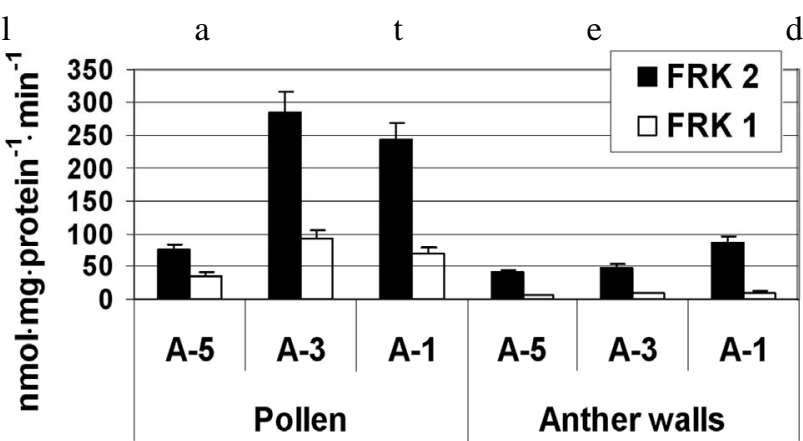

Figure 4. Activity of fructokinases (FRK) 1 and 2 at three stages of tomato cv. 3017 anther walls and pollen-grains maturation (A-5, A-3, A-1: 5, 3 and $1 \mathrm{~d}$ before anthesis, respectively). The detected activity might also include that of fructokinase 4. Data represent an average of 3 replicates. "Pollen" represents maturing microspores. Vertical bars represent SE.

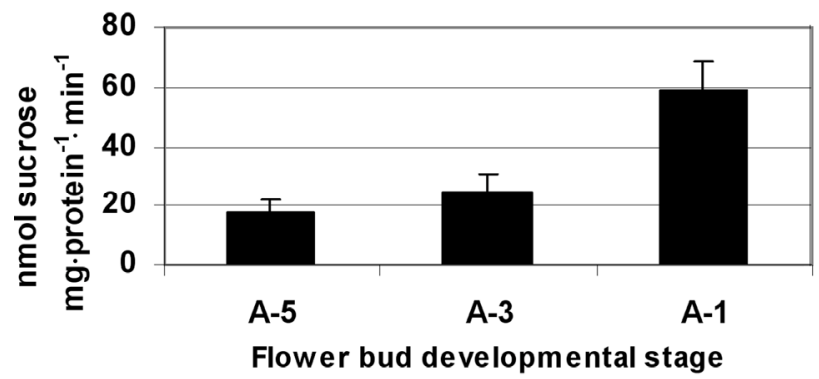

(a)

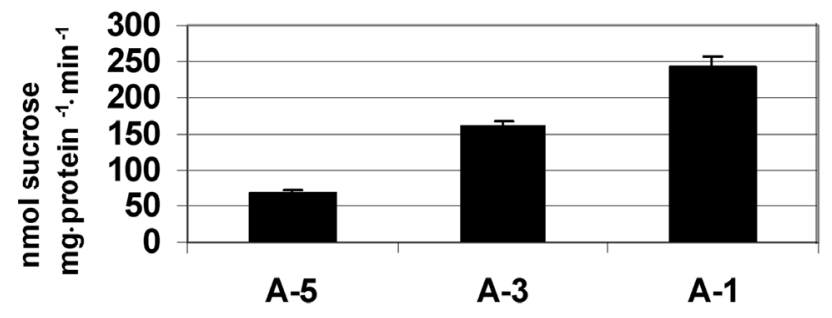

Flower bud developmental stage

(b)

Figure 5. Activity of SPS at three stages of tomato cv. 3017 anther walls (a) and pollen-grains (b) maturation (A-5, A-3, A-1: 5, 3 and $1 \mathrm{~d}$, pre-anthesis, respectively). Data represent an average of at least 3 biological replicates. Vertical bars represent $\mathrm{SE}$.

microspores, SPS activity was high and it resembled that of fructokinase 2, namely exhibiting a dramatic increase (over twofold) from stage A-5 to A-3 (Figure 5(b)).

A further increase in SPS enzymatic activity was detected at developmental stage A-1, close to flower opening, reaching $240 \mathrm{nmol}$ sucrose $\mathrm{mg} \cdot$ protein $^{-1} \cdot \mathrm{min}^{-1}$ (Figure $5(b))$.

\section{Discussion}


During microspore maturation, spatial and temporal changes in the levels and ratios of sucrose, glucose and fructose were detected in the four main parts of the stamen: the filament, anther wall, locular fluid and pollen grains. The data indicate the existence of a pathway in which sucrose molecules predominate at the starting point (the vascular bundles), and at the final point (the mature pollen grains) where sucrose was found to constitute at least $80 \%$ of the total soluble sugars (Figure 1), confirming previous data $[21,32,33]$. These results may suggest existence of a "futile cycle" of sucrose cleavage and synthesis, as suggested in the late phases of sorghum microspores development [34]. Breakdown of sucrose to hexoses was already occurring in the filaments, with further hydrolysis in the anther wall (Figures 1(a) and (b)). Three main enzymes are responsible for sucrose cleavage in the anther wall fraction: CWI, vacuolar invertase and Susy (Figure 3). The resultant hexoses-glucose and fructose - may be used for general metabolism and starch biosynthesis (Figure 2) or move on to the locular fluid. The relative high activity levels of the sucrose-cleaving enzymes, together with the low SPS activity may be the reason for the low sucrose-to-hexose ratio in the anther walls (Figures 1, 3 and 5).

It is interesting to note that in both the filament and anther wall tissues the fructose-to-glucose ration is close to 2:1, respectively, pointing to the possibility of preferential transport and utilization of glucose. The anther walls accumulated starch in addition to soluble sugars (Figure 2). Castro and Clement [8] suggested that the anther walls have a buffering function, regulating the availability of soluble sugars in the whole anther. Towards flower opening, starch levels decrease (Figure 2), and the resulting sugars may contribute to the increasing soluble sugars moving from the anther wall to the locular fluid (Figure 1).

The maturing pollen grains obtain their sugars directly from the locular fluid, since at the later stages of anther development the tapetum no longer exists [2,5]. Hoekstra and van Roekel [35] reported that Papaver-dubium pollen maturation during the last 3 days of development occurs independently from the parent plant. Nevertheless, it has been suggested that sugars move from the anther walls to the locular fluid at these late stages of anther development via the plasma membrane, which maintains its integrity during autolysis of the tapetum [36], and/or via the ML 1 layer of the anther wall which remains unchanged at this stage [2]. Polowick and Sawhney [5] found in tomato that already at the vacuolated microspore stage, the tapetal cells showed signs of degeneration and that at the binucleate pollen grain stage many of the tapetum cells contained no cytoplasm and fragments of wall material were observed between the tapetal wall and the developing microspores.

Clement et al. [7] stated that at the later stages of lily pollen development, the locules contain mainly pollenkitt, which consists of lipids and proteins. Castro and Clement [8], however, detected sugars in the locular fluid. The results of the present study also show that at the later stages of pollen development, the locular fluid is rich in soluble sugars. Moreover, it is interesting to note that unlike in the lily locular fluid where sucrose level was found to be much higher than those of the two hexoses [8] in both, tomato (Figure 1(c)) and pepper (data not shown), fructose was the major sugar in the locular fluid while sucrose was the minor one. Clement and Audran [2] raised the question of whether there is any kind of regulation of locular fluid composition during the anthermaturation phase. This question is also of interest to us since we do not yet know the reason for the dramatic increase in the relative concentration of fructose, which starts in the pepper filaments (data not shown) and tomato anther walls (Figure 1(b)) and reaches its maximum in the locular fluids of both species (Figure 1(c) and data not shown). The higher fructose-to-glucose levels in the locular fluid may be due to a lower preference/affinity of the pollen hexose transporters for fructose [37]. Carbohydrate composition of the locular fluid may also be regulated by the pollen apoplastic CWI enzyme, that hydrolyzes the sucrose molecules coming from the locular fluid, thus contributing or creating a "driving-force" for flow of sugars into the developing pollen grains [38].

The high activity levels of CWI observed in maturing microspores and the low activity of soluble invertase (Figure 3) support the results of Castro and Clement [8] with lily pollen grains. Those authors suggested that CWI activity is related to microspore and pollen-wall development. The important role of CWI in carbohydrate supply for the symplastically isolated pollen grains has also been demonstrated in tobacco [39] and in tomato, where the importance of extracellular invertase for sustaining growth and development of pollen as well as pollen germination and tube growth was indicated [40]. The results of the present paper emphasize the potential regulatory role of CWI during microspore maturation with respect to its contribution to microspores' sink strength.

As discussed above, in the maturing microspores and pollen grains, sucrose is re-synthesized and accumulates (Figure 1(d)). High fructokinase 2 and SPS activities during pollen maturation (Figures $\mathbf{4}$ and 5, respectively), coincided with sucrose accumulation. The increase in both SPS activity (Figure 5) and sucrose concentration, as well as the lack of detectable Susy activity (data not shown) raise the possibility that SPS mediates sucrose biosynthesis in maturing microspores and pollen grains. Furthermore, our data show that the pollen grains contain 
at least two functional fructokinases (Figure 4), which may metabolize the fructose entering the microspores/ pollen grains for further utilization. Karni and Aloni [41] suggested that in pepper pollen, fructokinase may function either to provide fructose-6-P for glycolysis or, through conversion to UDP-glucose, to support the biosynthesis of cell-wall material for pollen-tube growth. The similar activity patterns of SPS and fructokinase 2 during pollen maturation that was observed in the present study suggest a role for fructokinase in providing fructose-6-P for sucrose synthesis. German et al. [20] reported the isolation of fructokinase 4 in mature anthers of tomato. It is plausible, therefore, that the detected activities of fructokinase 1 and 2 also include that of fructokinase 4 . It should be noted that under the same reaction conditions, no hexokinase activity was detected (data not shown).

The accumulated sucrose, besides being the main energy source for germination, may function as an osmolyte $[42,43]$ in protecting pollen membranes and proteins during pollen dehydration or during exposure to stress conditions such as high temperatures. Pacini et al. [44] stressed the importance of pollen carbohydrates in regulating the water balance with the surrounding environment and maintaining pollen viability over time. High sucrose content in the maturing and mature pollen grains has been suggested to be associated with the acquisition of germination capacity and desiccation tolerance, as it provides the necessary osmolality for cell expansion [35] or is related to pollen longevity [45]. Buitink and Leprince [46] suggested that sucrose participates in the formation of intracellular glasses which protect membranes during dehydration. Vesprini et al. [47] suggest a role of cytoplasmic pollen carbohydrates in resistance to low temperature exposure.

\section{Acknowledgements}

This work was supported by the Chief Scientist of the Israeli Ministry of Agriculture (261-0660-08).

\section{REFERENCES}

[1] W. Eschrich, "Phloem Unloading Following Reactivation in Predarkened Mature Maize Leaves,” Planta, Vol. 161, No. 2, 1984, pp. 113-119. doi:10.1007/BF00395470

[2] C. Clement and J. C. Audran, "Anther Wall Layers Control Pollen Sugar Nutrition in Lilum,” Protoplasma, Vol. 187, No. 1-4, 1995, pp. 172-181. doi:10.1007/BF01280246

[3] C. Clement, P. Mischler, M. Burrus and J. C. Audran, "Characteristics of the Photosynthetic Apparatus and $\mathrm{CO}_{2}$ Fixation in the Flower Bud of Lilium. I. Corolla," International Journal of Plant Sciences, Vol. 158, No. 6, 1997, pp. 794-800. doi:10.1086/297492
[4] R. B. Goldberg, T. P. Beals and P. M. Sanders, “Anther Development: Basic Principles and Practical Applications,” The Plant Cell, Vol. 5, No. 10, 1993, pp. 1217 1229.

[5] P. L. Polowick and V. K. Sawhney, "Defferentiation of the Ttapetum during Microsporogenesis in Tomato ( $L y$ copersicon esculentum Mill.), with Special Reference to the Tapetal Cell Wall,” Annals of Botany, Vol. 72, No. 6, 1993, pp. 595 -605. doi:10.1006/anbo.1993.1150

[6] G. Suzuki, "Recent Progress in Plant Reproduction Research: The Story of the Male Gametophyte Through to Successful Fertilization,” Plant and Cell Physiology, Vol. 50, No. 11, 2009, pp. 1857-1864. doi:10.1093/pcp/pcp142

[7] C. Clement, P. Laporte and J. C. Audran, "The Loculus Content and Tapetum during Pollen Development in Lilium,” Sexual Plant Reproduction, Vol. 11, No. 1, 1998, pp. 94-106.

[8] A. J. Castro and C. Clement, "Sucrose and Starch Catabolism in the Anther of Lilium during Its Development: A Comparative Study among the Anther Wall, Locular Fluid and Microspore/Pollen Fractions,” Planta, Vol. 225, No. 6, 2007, pp. 1573-1582. doi:10.1007/s00425-006-0443-5

[9] N. J. Kruger, "Carbohydrate Synthesis and Degradation,” In: D. T. Dennis and D. H. Turpin, Eds., Plant Physiology, Biochemistry and Molecular Biology, Longman Scientific and Technical, Harlow, 1990, pp. 59-79.

[10] Z. Tymowska-Lalanne and M. Kreis, "The Plant Invertases: Physiology, Biochemistry and Molecular Biology,” Advances in Botanical Research, Vol. 28, No. 1, 1998, pp. 71-117. doi:10.1016/S0065-2296(08)60294-3

[11] A. Strum, D. Hess, H. S. Lee and S. Lienhard, "Neutral Invertase is a Novel Type of Sucrose-Cleaving Enzyme," Physiologia Plantarum, Vol. 107, No. 2, 1999, pp. 159165. doi:10.1034/j.1399-3054.1999.100202.x

[12] J. Q. Chen and C. C. Black, "Biochemical and Immunological Properties of Alkaline Invertase Isolated from Sprouting Soybean Hypocotyls," Archives of Biochemistry and Biophysics, Vol. 295, No. 1, 1992, pp. 61-69. doi:10.1016/0003-9861(92)90488-I

[13] J. Y. Park, T. Canam, K. Y. Kang , D. D. Ellis and S. D. Mansfield, "Over-Expression of an Arabidopsis Family a Sucrose Phosphate Synthase (SPS) Gene Alters Plant Growth and Fibre Development," Transgenic Research, Vol. 17, No. 2, 2008, pp. 181-192. doi:10.1007/s11248-007-9090-2

[14] P. Geigenberger, R. Reimholz, M. Geiger, L. Merlo, V. Canale and M. Stitt, "Regulation of Sucrose and Starch Metabolism in Potato Tubers in Response to Short-term Water Deficit,” Planta, Vol. 201, No. 4, 1997, pp. $502-$ 518. doi:10.1007/s004250050095

[15] S. C. Huber and J. L. Huber, "Role and Regulation of Sucrose Phosphate Synthase in Higher Plants," Annual Review of Plant Physiology and Plant Molecular Biology, Vol. 47, No. 1, 1996, pp. 431-444. doi:10.1146/annurev.arplant.47.1.431 
[16] S. Chen, M. Hajirezaei and F. Börnke, "Differential Expression of Sucrose-Phosphate Synthase Isoenzymes in Tobacco Reflects their Functional Specialization during Dark-Governed Starch Mobilization in Source Leaves,” Plant Physiology, Vol. 139, No. 3, 2005, pp. 1163-1174. doi:10.1104/pp.105.069468

[17] C. J. Baxter, C. H. Foyer, J. Turner, S. A. Rolfe and W. P. Quick, "Elevated Sucrose-Phosphate Synthase Activity in Transgenic Tobacco Sustains Photosynthesis in Older Leaves and Alters Development,” Journal of Experimental Botany, Vol. 54, No. 389, 2003, pp. 1813-1820. doi:10.1093/jxb/erg196

[18] M. M. Laporte, J. A. Galagan, A. L. Prasch, P. J. Vanderveer, D. T. Hanson, C. K. Shewmaker and T. D. Sharkey, "Promoter Strength and Tissue Specificity Effects on Growth of Tomato Plants Transformed with Maize Sucrose-Phosphate Synthase,” Planta, Vol. 212, No. 5-6, 2001, pp. 817-822. doi:10.1007/s004250000433

[19] C. H. Haigler, M. Ivanova-Datcheva, P. S. Hogan, V. V. Salnikov, S. Hwang, K. Martin and D. P. Delmer, "Carbon Partitioning to Cellulose Synthesis," Plant Molecular Biology, Vol. 47, No. 1-2, 2001, pp. 29-51. doi:10.1023/A:1010615027986

[20] M. A. German, N. Dai, I. Chmelnitsky, I. Sobolev, Y. Salts, R. Barg, A. A. Schaffer and D. Granot, "LeFRK4, a Novel Tomato (Lycopersicon esculentum Mill.) Fructokinase Specifically Expressed in Stamens," Plant Science, Vol. 163, No. 3, 2002, pp. 607-613. doi:10.1016/S0168-9452(02)00170-X

[21] E. Pressman, M. M. Peet and D. M. Pharr, "The Effect of Heat Stress on Tomato Pollen Characteristics Is Associated with Changes in Carbohydrate Concentration in the Developing Anthers," Annals of Botany, Vol. 90, No. 5, 2002, pp. 631-636. doi:10.1093/aob/mcf240

[22] V. K. Sawhney and S. K. Bhadula, "Microsporogenesis in the Normal and Male-Sterile Stamenless-2 Mutant of Tomato (Lycopersicon esculentum)," Canadian Journal of Botany, Vol. 866, No. 10, 1988, pp. 2013-2021.

[23] N. Aouali, P. Laporte and C. Clement, "Pectin Secretion and Distribution in the Anther during Pollen Development in Lilium,” Planta, Vol. 213, No. 1, 2001, pp. 71-79. doi:10.1007/s004250000469

[24] N. L. Hubbard, D. M. Pharr and S. C. Huber, "Role of Sucrose Phosphate Syntase in Sucrose Biosynthesis in Ripening Bananas and its Relationship to the Respiratory Climacteric,” Plant Physiology, Vol. 94, No. 1, 1990, pp. 201-208. doi:10.1104/pp.94.1.201

[25] J. M. H. Stoop and D. M. Pharr, "Mannitol Metabolism in Celery Stressed by Excess Macronutrients," Plant Physiology, Vol. 106, No. 2, 1994, pp. 503-511.

[26] D. Miron, M. Petreikov, N. Carmi, S. Shen, I. Levin, D. Granot, E. Zamski and A. A. Schaffer, "Sucrose Uptake, Invertase Localization and Gene Expression in Developing Fruit of Lycopersicon esculentum and the Sucrose-Accumulating Lycopersicon hirsutum,” Physiologia Plantarum, Vol. 115, No. 1, 2002, pp. 35-47. doi:10.1034/j.1399-3054.2002.1150104.x

[27] A. A. Schaffer, B. Aloni and E. Fogelman, "Sucrose Me- tabolism in Developing Fruit of Cucumis,” Phytochemistry, Vol. 26, No. 7, 1987, pp. 1883-1887. doi:10.1016/S0031-9422(00)81721-5

[28] G. L. Miller, "Use of Dinitrosalicylic Acid Reagent for Determination of Reducing Sugars," Analytical Chemistry, Vol. 31, No. 3, 1959, pp. 426-428. doi:10.1021/ac60147a030

[29] M. M. Bradford, “A Rapid and Sensitive Method for the Quantitation of Microgram Quantities of Protein Using the Principle of Dye Binding," Analytical Biochemistry, Vol. 72, No. 1-2, 1976, pp. 143-147. doi:10.1016/0003-2697(76)90527-3

[30] A. A. Schaffer and M. Petreikov, "Sucrose to Starch Metabolism in Tomato Fruit Undergoing Transient Starch Accumulation,” Plant Physiology, Vol. 113, No. 3, 1997, pp. 739-746.

[31] N. L. Hubbard, S. C. Huber and D. M. Phar, "Sucrose Phosphate Synthase and Acid Invertase as Determinants of Sucrose Concentration in Developing Muskmelon (Cucumis melo L.) Fruits,” Plant Physiology, Vol. 91, No. 4, 1989, pp. 1527-1534. doi:10.1104/pp.91.4.1527

[32] R. Shaked, K. Rosenfeld and E. Pressman, "The Effect of Low Night Temperatures on Carbohydrate Metabolism in Developing Pollen Grains of Pepper in Relation to their Number and Functioning," Scientia Horticulturae, Vol. 102, No. 1, 2004, pp. 29-36. doi:10.1016/j.scienta.2003.12.007

[33] N. Firon, R. Shaked, M. M. Peet, D. M. Pharr, E. Zamski, K. Rosenfeld, L. Althan and E. Pressman, "Pollen Grains of Heat Tolerant Tomato Cultivars Retain Higher Carbohydrate Concentration Under Heat Stress Conditions,” Scientia Horticulturae, Vol. 109, No. 3, 2006, pp. 212-217. doi:10.1016/j.scienta.2006.03.007

[34] M. Jain , P. V. Prasad , K. J. Boote , A. L. Hartwell Jr. and P. S. Chourey, "Effects of Season-Long High Temperature Growth Conditions on Sugar-to-Starch Metabolism in Developing Microspores of Grain Sorghum (Sorghum bicolor L. Moench),” Planta, Vol. 227, No. 1, 2007, pp. 67-79. doi:10.1007/s00425-007-0595-y

[35] F. A. Hoekstra and T. van Roekel, "Dessication Tolerance of Papaver-dubium Pollen during Its Development in the Anther-Possible Role of Phospholipid Composition and Sucrose Content,” Plant Physiology, Vo. 88, No. 3, 1988, pp. 626-632. doi:10.1104/pp.88.3.626

[36] S. A. Reznickova and H. G. Dickinson, "Ultrastructural Aspects of Storage Lipid Mobilization in the Tapetum of Lilium hybrida var. Enchantment,” Planta, Vol. 155, No. 5, 1982, pp. 400-408. doi:10.1007/BF00394468

[37] J. Hirsche, T. Engelke, D. Völler, M. Götz and T. Roitsch, "Interspecies Compatibility of the Anther Specific Cell Wall Invertase Promoters from Arabidopsis and Tobacco for Generating Male Sterile Plants,” Theoretical and Applied Genetics, Vol. 118, No. 2, 2009, pp. 235-245. doi:10.1007/s00122-008-0892-2

[38] T. Engelke, J. Hirsche and T. Roitsch, "Metabolically Engineered Male Sterility in Rapeseed (Brassica napus L.),” Theoretical and Applied Genetics, Vol. 122, No. 1, 
2010, pp. 163-174. doi:10.1007/s00122-010-1432-4

[39] M. Goetz, D. E. Godt, A. Guivarc’h, U. Kahmann, D. Chriqui and T. Roitsch, "Induction of Male Sterility in Plants by Metabolic Engineering of the Carbohydrate Supply," Proceedings of the National Academy of Sciences USA, Vol. 98, No. 11, 2001, pp. 6522-6527. doi:10.1073/pnas.091097998

[40] R. K. Proels, M. C. Gonzalez and T. Roitsch, "GibberellinDependent Induction of Tomato Extracellular Invertase Lin7 Is Required for Pollen Development,” Functional Plant Biology, Vol. 33, No. 6, 2006, pp. 547-554. doi:10.1071/FP04146

[41] L. Karni and B. Aloni, "Fructokinase and Hexokinase from Pollen Grains of Bell Pepper (Capsicum annum L.): Possible Role in Pollen Germination under Conditions of High Temperature and $\mathrm{CO}_{2}$ Enrichment," Annals of Botany, Vol. 90, No. 5, 2002, pp. 607-612. doi:10.1093/aob/mcf234

[42] M. Seki, T. Umezawa, K. Urano and K. Shinizaki, "Regulatory Metabolic Networks in Drought Stress Responses," Current Opinion in Plant Biology, Vol. 10, No. 3, 2007, pp. 296-302. doi:10.1016/j.pbi.2007.04.014

[43] A. Mukaiyama, Y. Koga, K. Takano and S. Kayana,
"Osmolyte Effect on the Stability and Folding of a Hyperthermophilic Protein, Proteins: Structure," Function and Genetics, Vol. 71, No. 1, 2008, pp. 110-118. doi:10.1002/prot.21660

[44] E. Pacini, M. Guarnieri and M. Nepi, "Pollen Carbohydrates and Water Content during Development, Presentation, and Dispersal: A Short Review," Protoplasma, Vol. 228, No. 1-3, 2006, pp. 73-77. doi:10.1007/s00709-006-0169-z

[45] A. Speranza, G. L. Calzoni and E. Pacini, “Occurrence of Mono- or Disaccharides and Polysaccharide Reserves in Mature Pollen Grains,” Sexual Plant Reproduction, Vol. 10, No. 2, 1997, pp. 110-115. doi:10.1007/s004970050076

[46] J. Buitink and O. Leprince, "Glass Formation in Plant Anhydrobiotes: Survival in the Dry State,” Cryobiology, Vol. 48, No. 3, 2004, pp. 215-228. doi:10.1016/j.cryobiol.2004.02.011

[47] J. L. Vesprini, M. Nepi, L. Cresti, M. Guarnieri and E. Pacini, "Changes in Cytoplasmic Carbohydrate Content During Helleborus Pollen Presentation,” Grana, Vol. 41, No. 1, 2002, pp. 16-20. doi:10.1080/00173130260045459 